\title{
El linchamiento de Berenice. Violencia de género e impunidad
}

\section{Berenice's lynching. Gender violence and impunity}

doi: http://dx.doi.org/10.32870/

espiral.v25i72.5405

Sergio Alberto López Molina

\begin{abstract}
Resumen
Este artículo reconstruye los hechos ocurridos durante el linchamiento de una mujer en la población de Metepec, municipio de Ocuituco, Estado de Morelos, a partir de las notas publicadas en diarios locales digitales. Se incorporan la narración del suceso y los comentarios publicados por los usuarios de las páginas con respecto a la noticia, y mediante análisis crítico del discurso se dilucida cómo es que confluyen la violencia de género provocada por los estereotipos, prejuicios y creencias sobre la idealización de la mujer y la impunidad prevaleciente por el esquema de justicia institucional. Finalmente, se proponen estrategias de intervención generales para disminuir los casos de linchamiento. Los resultados abonan al conocimiento de temas como la violencia colectiva y de género y el análisis de aspectos jurídicos en los casos de linchamiento.
\end{abstract}

Palabras clave: linchamiento, violencia de género, violencia colectiva, impunidad, género.

\begin{abstract}
This article reconstructs the events in the lynching of a woman in Metepec, municipality of Ocuituco, in the state of Morelos, Mexico, by notes issued by local digital newspapers. The account of the event and the comments posted by users of the websites regarding the news are incorporated, and through critical discourse analysis, it is clarified how gender violence caused by stereotypes, prejudices and beliefs about the idealization of women and the prevailing impunity for the scheme of institutional justice come together. Finally, general intervention strategies are proposed to reduce cases of lynching.The results provide the knowledge of issues such as collective violence and gender and the analysis of legal issues in cases of lynching.
\end{abstract}

Keywords: lynching, gender violence, collective violence, impunity, gender.

-Profesor-Investigador de la Facultad de Psicología de la Universidad de Colima, México. ORCID: http://orcid.org/0000-0002-34|8-2864_sergio_lopez@ucol.mx

Fecha de recepción: 08 de abril de 2016. Fecha de aceptación: 07 de diciembre de 2017. 


\section{Linchamiento, el problema que anuda}

La violencia es un tema preponderante en las agendas de los distintos países del mundo. Al respecto, la Organización Mundial de la Salud (OMS) menciona que la violencia está tan presente que se le percibe a menudo como un componente ineludible de la condición humana (OMS, 2002). Los medios de comunicación actuales permiten que la violencia generada en cualquier parte del mundo se conozca en muy poco tiempo, mostrando acciones que van desde la violencia autoinfligida hasta la colectiva.

La OMS define la violencia como "el uso deliberado de la fuerza física o el poder, ya sea en grado de amenaza o efectivo, contra uno mismo, otra persona o un grupo o comunidad, que cause o tenga muchas probabilidades de causar lesiones, muerte, daños psicológicos, trastornos del desarrollo o privaciones" (OMS, 2002). También especifica tres grandes categorías según el autor del acto: violencia dirigida contra uno mismo, violencia interpersonal y violencia colectiva.

Así, la violencia colectiva se precisa como el uso instrumental de la violencia por personas que se identifican a sí mismas como miembros de un grupo frente a otro grupo o conjunto de individuos, con objeto de alcanzar objetivos políticos, económicos o sociales. Adopta diversas formas: conflictos armados dentro de los Estados o entre ellos; genocidio, represión y otras violaciones de los derechos humanos; terrorismo; y crimen organizado (OMS, 2002).

En específico, el linchamiento representa una forma de instrumentación de la violencia colectiva en el que un conjunto de individuos se plantea el objetivo de castigar en público, sin proceso judicial formal, a un sospechoso de haberlos agraviado en algún aspecto económico, social o político, y en el que ejecutan al instante un castigo que el propio colectivo determina. 
Cuando la masa se reúne para ejecutar un linchamiento, el objetivo y el fin no quedan claros en un inicio. La convocatoria es a partir de campanadas o de boca en boca; el mensaje sobre la razón para la cual se convoca se va distorsionando y exagerando. El chisme funciona como la fuente de comunicación, distribuyendo de manera rápida un mensaje que enfatiza una interpretación negativa, lo que incrementa el éxtasis de la turba. El linchado no sólo recibe una condena por el acto cometido, sino por la distorsión del mensaje emitido entre los linchadores.

Una parte importante del linchamiento reside en el ritual de enjuiciamiento y ejecución del castigo. En esta relación, el poder reside en los ejecutores del ritual, mientras que el ejecutor del delito -victimario aparente de inicio, y luego víctima- tiene pocas posibilidades de ser escuchado o de que sus súplicas y explicaciones redunden en un juicio justo. Se presenta entonces una escenificación que incluye la tortura y la ejecución pública, y cuyo objetivo es mostrar las consecuencias, a quienes se sientan tentados a hacerlo, de no obedecer (Muchembled, 2010).

En este proceso, resulta relevante considerar la violencia física y psicológica que se utiliza antes y durante el interrogatorio como una forma de acceso a la verdad, es decir, a la confesión del delito cometido por parte del presunto delincuente. En palabras de Muchembled (2010), la tortura y el tipo de castigo se determinan por la condición del sujeto a partir de la simple presunción: si se considera que las pruebas son insuficientes, se procede a la tortura para obtener una confesión en la que la declaración del supuesto culpable representa lo que la turba desea escuchar, y no revela lo que verdaderamente ocurrió. En el momento en que se menciona algo que no es lo esperado, el castigo físico se incrementa, hasta que el individuo, hombre o mujer, acepta que es culpable y delata a otros participantes. 
En los linchamientos, hay un proceso oculto relacionado con la percepción sobre la justicia impartida por las instituciones de seguridad gubernamentales y correspondiente al esquema de impunidad que prevalece en los procesos judiciales en México, percepción provocada por la corrupción y las lagunas en materia legal que dejan un claro sentimiento de impotencia en las víctimas de delitos. Es en este ambiente donde hacer justicia por propia mano cobra sentido y se presenta como una necesidad, con el imaginario de que mediante ese tipo de justicia se obtiene pronto un castigo ejemplar para quien delinque, a la vista de los afectados y de la población.

Estas son algunas de las razones por las que en los linchamientos la violencia se desborda, originada por reflejos de impotencia sobre la percepción de un grupo de personas respecto a la falta de impartición pronta de justicia, ante la cual el grupo busca que el castigo resulte ejemplar y acorde a los delitos cometidos. Sin embargo, los linchamientos de supuestos delincuentes se realizan sin tomar en cuenta la importancia de la falta cometida:

En menos de seis meses, se registraron trece linchamientos en los municipios de Morelos, los motivos son: robar una casa, robar metros de cable telefónico, asaltar una tienda, asaltar [a] un taxista, asaltar [a] una persona, asaltar [a] un taquero, asaltar una ruta; golpear a un hombre[;] y exigir el pago por el derecho de piso a un carnicero (De la Fuente, 20I3c).

Es necesario considerar en el proceso previo al linchamiento la existencia de aspectos culturales arraigados, como estereotipos, prejuicios, creencias, además de factores sociales y económicos, que definen el movimiento colectivo. Es en este punto donde se hacen presentes los aspectos de género y su relación con la violencia física y estructural como esquemas de represión, supresión y rechazo que incitan a eliminar y ocultar los estereotipos no deseados, por ejemplo, 
los contrarios a una buena mujer en el contexto mexicano actual; esta necesidad de desaparición de lo no deseado ha generado sistemas de represión-eliminación propios de la sociedad (Foucault, 2010).

Así, la violencia contra la mujer está definida como "todo acto de violencia de género que resulte, o pueda tener como resultado un daño físico, sexual o psicológico para la mujer, inclusive las amenazas de tales actos, la coacción o la privación arbitraria de libertad, tanto si se producen en la vida pública como en la privada" (OMS, 2016).

Con la violencia de género ejercida en algunos casos de linchamientos de mujeres, se busca preservar un orden de relaciones basado en la explotación de las mujeres por parte de los hombres. De esta forma, el caso de Berenice fue seleccionado para este trabajo porque en él se ponen en juego los aspectos culturales con respecto al género. Los aspectos que hemos enunciado anteriormente como que anteceden al linchamiento son los que marcan esta pauta, pues para la turba Berenice representaba lo contrario a la idealización de la mujer, siendo catalogada por la misma como una mujer sin escrúpulos que al intentar robar un niño reveló una falta de conciencia sobre lo que es ser buena madre, además de que su estado de ebriedad o drogadicción fue considerado por la turba como contrario a las normas de recato.

Para la selección del caso, se consideró la singularidad de la noticia y las distintas formas en que se redactaron las notas tanto del suceso como de su seguimiento, características que permitían un análisis profundo. También influyó el hecho de que el caso de Berenice pertenece a los de una clase social subalterna, que incluye a aquel conjunto de sujetos que no forman parte del grupo en el poder o la clase dominante, y que por lo tanto resultan una clase ignorada, poco estudiada pues poco importa (Gizburg, 2001).

Con tales aspectos, el caso de Berenice connota un esquema de control del orden social, que funciona como una 
inmensa máquina simbólica que tiende a ratificar la dominación masculina en la que se apoya (Bourdieu, 2010), pues lleva implícito un mensaje para las mujeres: es lo que puede ocurrirles si no se alinean al comportamiento correctamente establecido, comportamiento dado por el esquema patriarcal impuesto-adoptado y en el que la violencia contra las mujeres se ha vuelto algo cotidiano y las estrategias para resolver conflictos de manera pacífica han quedado descartadas ante la necesidad de mostrar públicamente -como espectáculola no tolerancia a eventos delictivos, evadiéndose así los esquemas de justicia del Estado y potenciándose la justicia por propia mano, con agresividad, banalidad y subjetividad, en la que el sexo masculino es mayoritariamente el agente y el femenino el objeto y receptor pasivo (Sánchez, 2007).

\section{Berenice y su narración}

Para determinar el desarrollo de los acontecimientos, se unificaron las distintas notas encontradas, buscando pretextos de análisis a partir de los sujetos que, como protagonistas, sintetizan, desde la posición que ocupan, el conjunto de determinaciones sociales y culturales que los constituyen (Lagarde, 2011). Se privilegió que los hechos se analizaran de manera conjunta, evitando la pérdida del marco de referencia del contexto y los aspectos culturales en los que se desarrolla la trama. Esta tarea fue complementada con el análisis de los comentarios emitidos en foros y redes sociales anexos a la noticia en versión digital, donde se encontraron las opiniones de distintas personas que leyeron la nota y que con sus comentarios fijaron una postura al respecto.

De las distintas fuentes de noticias relacionadas con el suceso de Berenice, se obtuvieron tramas narrativas individuales, que en conjunto se entretejieron para completar y solventar la falta de información de algunos relatos, lo que 
permitió la reunión de elementos heterogéneos y obtener la inteligibilidad con miras a la concordancia de la trama que permitiera identificar una configuración única (Ricoeur, 2009). La intención era dar cuenta de lo acontecido en esos días, reconstruyendo y completando los episodios con detalles e incidentes discordantes y concordantes que otorgaran aspectos a analizar (Tornero, 2008). Por su parte, la repetición implica un énfasis en ciertas acciones que permite lograr aseveraciones y disminuir las interpretaciones aventuradas.

Debido a que el control de la mente y de la acción es lo que define el poder, el control del discurso confirma y extiende el poder de los grupos dominantes y contribuye a la confirmación, o incluso al incremento, del desequilibrio en la igualdad social. Así, resulta innegable que los hombres disponen, en detrimento de las mujeres, del control sobre la mayor parte de las formas del discurso público, y que tal control contribuye indirectamente al machismo y al sexismo (Van Dijk, 2009).

Por lo anterior, la narración del suceso y los comentarios fueron analizados a través del análisis crítico del discurso (Iñiguez, 2003), con el cual se revisaron el significado, la referencia y la interpretación de frases específicas identificadas como de alto de valor interpretativo, pues se considera que el discurso no solamente expresa, sino que también construye y confirma prejuicios, contribuyendo a su reproducción y jugando un papel crucial en la expresión y la (re)producción de cogniciones sociales que los miembros del grupo comparten y que regulan y controlan sus actos e interacciones (Van Dijk, 2002). Cabe aclarar que la interpretación es de tercer o cuarto nivel, porque tal y como lo especifica Geertz (2005), se requeriría ser integrante de esa población analizada para dar una interpretación de primer orden. En el siguiente apartado se muestra el resultado de la estructuración de la narración. 


\section{I. La narración de los hechos}

En la localidad de Metepec, en el municipio de Ocuituco, estado de Morelos, la noche del miércoles 17 de julio de 2013, Berenice Elizabeth Rojas Castillo caminaba por las calles, introduciéndose en distintas casas habitación. Al entrar en una de ellas, un grupo de mujeres la acusó: "está drogada, se metió a varias casas y aquí intentó secuestrar a la niña" (Agencia Reforma, 2013). De inmediato, la mujer fue retenida mientras los pobladores de la comunidad se pasaban la voz sobre la detención de una presunta secuestradora. Acto seguido, hicieron sonar la campana de la iglesia para congregar a un mayor número de personas.

Inicialmente, acudieron cerca de sesenta personas (Agencias, 2013), que se transmitían unas a otras la versión de los hechos. Entre hombres y mujeres, comenzaron a golpear a Berenice mientras la cuestionaban sobre las razones por las que pretendía secuestrar a la niña. Tras cada respuesta dada por Berenice, la mujer recibía golpes en cara y cuerpo. $\mathrm{Al}$ solicitar respuestas, sostenían su cabeza por la cabellera, y si tardaba en responder era abofeteada y golpeada a puño cerrado (Rojas, 2013a).

Durante el interrogatorio, se iban sumando los agresores, al punto de que ya no existía un orden entre las preguntas, los golpes y las respuestas: había gritos, acusaciones y propuestas de castigo. Berenice, en un principio, intentó responder lo que le cuestionaban, pero los golpes la debilitaron hasta quedar semiinconsciente. Esta situación molestó más a los inquisidores, pues supusieron que fingía dicho estado para evitar seguir siendo castigada. Entre la información obtenida, se enteraron que provenía de Yautepec (Agencias, 2013; La Policiaca, 2013; Rojas, 2013a; Tonantzin, 2013), había estado bebiendo e intentaba volver a casa. Sobre el intento de secuestro, Berenice no mencionó nada, tampoco dijo su nombre.

\section{8}


Los pobladores decidieron recluir a Berenice en una celda ubicada en el atrio de la iglesia de La Concepción, en su mismo poblado, para que no escapara (Agencias, 2013; La Policiaca, 2013; Rojas, 2013a; Tonantzin, 2013). Al momento de dicha decisión, ya se habían reunido trescientos residentes de Metepec (La Policiaca, 2013). Ante la petición grupal de que se hiciera justicia, la mujer siguió siendo amenazada, interrogada y golpeada en el interior de la celda. El proceso inquisitorio y de tortura duró hora y media, tras lo cual el cuerpo inerte de Berenice fue trasladado a la calle Vicente Guerrero (De la Fuente, 2013a), recibiendo golpes directos o siéndole arrojados piedras, palos y diversos objetos por parte de la gente que pasaba.

Los miembros del grupo llegaron frente a la escuela Benito Juárez, en donde Berenice fue subida en una barda y le fue colocada una soga en el cuello. Sin embargo, intentando defenderse sujetó la cuerda y cayó de una altura aproximada de tres metros sobre el asfalto (Rojas, 2013a). El acto enfureció aún más a los pobladores, quienes golpearon brutalmente a Berenice, hasta dejarla de nuevo inconsciente (Agencia Informativa, 2013).

Fue hasta la medianoche cuando uno de los vecinos reportó a la policía: "los pobladores de Ocuituco tienen retenida una mujer, la están golpeando, ya se encuentra inconsciente y amenazan con matarla" (Agencias, 2013; González, 2013). Primero asistió la policía estatal, pero el arresto de Berenice les fue impedido argumentando: "estará libre al día siguiente, el acto quedará impune o no se aplicará la justicia con rigor" (Rojas, 2013a). Ante esta negativa, los policías estatales llamaron al Ejército, que al presentarse impidió que siguieran lastimando el cuerpo inconsciente de Berenice. También, al enterarse de la situación, se presentó el presidente municipal, quien dialogó con los habitantes y prometió que la mujer sería puesta a disposición del agente del ministerio público (Rojas, 2013a). 
En el proceso de diálogo, se logró convencer a los pobladores de que entregaran a la mujer. El personal del servicio médico de Ocuituco ingresó a la zona e inició la atención de Berenice, que posteriormente fue trasladada al Hospital General de Cuautla con un delicado estado de salud provocado por los golpes que recibió (Rojas, 2013a). En el expediente se anotó: "no pudo proporcionar ningún dato personal" (De la Fuente, 2013a). El informe de la mañana siguiente indicó: "La mujer continúa en estado crítico, y por consiguiente no ha podido proporcionar sus generales, quedando hasta el momento en calidad de desconocida" (Rojas, 2013a).

El domingo 21 de julio de 2013, las autoridades ministeriales declararon:

la mujer permanece en estado de coma debido a los golpes y lesiones que presentó en el cuerpo, principalmente en la cabeza, por lo que permanece bajo observación médica en el área de terapia intensiva del Hospital General de Cuautla: "Está muy grave, los golpes que recibió en la cabeza originaron que se encuentre en coma, los médicos están esperando que evolucione clínicamente de manera satisfactoria, así tendremos oportunidad de entrevistarla para saber su versión en torno a los hechos, se queda a la espera de que en las próximas horas ya pueda declarar o al menos, familiares o amigos la identifiquen" (De la Fuente, 2013b).

Ese mismo día, el gobernador de Morelos justificó y minimizó el hecho en una declaración pública, descartando que hubiera brotes violentos por parte de los pobladores de la zona oriente (En serio noticias, 2013). Al siguiente día, Berenice murió en el hospital (Carrillo, 2013a).

El miércoles 24 de julio de 2013, el ministerio público solicitó a un juez cuatro órdenes de aprehensión en contra del mismo número de sujetos, identificados como los principales agresores de Berenice. Las autoridades ministeriales declararon al respecto: "En un inicio se les imputaba el delito de homicidio en grado de tentativa, pero ya cambió 
porque la mujer falleció a consecuencia de las lesiones que estos sujetos le propiciaron, entonces ya solicitamos al juez una orden de aprehensión por el homicidio para estos cuatro sujetos que ya están plenamente identificados" (Staff, 2013).

El cadáver de Berenice permaneció durante varios días en las instalaciones de la Subprocuraduría de Justicia de la región oriente. El jueves 8 de agosto de 2013, fue identificada por su madre como Berenice Elizabeth, de 23 años de edad, con domicilio en el municipio de Yautepec (Carrillo, 2013a).

Ante el conocimiento de las órdenes de aprehensión, el miércoles 14 de agosto de 2013 los habitantes del poblado de Metepec en el municipio de Ocuituco solicitaron a la entonces Secretaría de Seguridad Pública una reunión de trabajo para tratar temas de seguridad y justicia. Durante la reunión, los pobladores le anticiparon a la secretaría que no admitirían una sanción por tomar justicia por propia mano si las autoridades no atendían su petición en materia de seguridad y justicia (La Policiaca, 2013b).

Para el lunes 26 de agosto de 2013, después de distintas reuniones de trabajo entre los vecinos y la secretaría, las investigaciones sobre el linchamiento en Metepec se frenaron bajo los siguientes acuerdos: 1) los vecinos denunciarían cualquier irregularidad, 2) ciudadanos y autoridades trabajarían de manera coordinada en materia de seguridad, y 3) la policía estatal implementaría más operativos y permanecería en la zona para evitar el robo de cosechas (Carrillo, 2013b).

\section{2. Antecedentes de la turba}

Todos los grupos sociales comparten rasgos significativos. Los pobladores de Ocuituco comparten la misma zona geográfica, una condición económica similar y la percepción de la injusticia por la impunidad de los delincuentes locales, lo que hace que comiencen una filiación y se genere un nosotros con posibilidades de reunirse y un los otros de los 
que hay que defenderse, es decir, un en este barrio (nosotros) linchamos ladrones (los otros). Esta situación se expone en la siguiente nota:

El hartazgo ciudadano generado por la inseguridad que se vive en Morelos ha provocado ya un silencioso levantamiento social en contra de la delincuencia [...] donde los propios ciudadanos de esas comunidades han decidido hacerse justicia por su propia mano. La "ley del talión" es evidente ya en una sociedad cansada y sin autoridad [...] [donde se evidencia] el hartazgo ciudadano de tanta inseguridad, que el Gobierno no ha podido mitigar [...]. En Morelos, la vida no vale nada. La "ley del talión" está permitida y está vigente más que en aquellas épocas de las tribus y hordas. En Ocuituco y en Jiutepec, quien delinque $\circ$ intenta delinquir está condenado a morir sin ningún recato (Millán, 2013).

Otro aspecto que potencia la afiliación son las acciones implementadas por los gobernantes y por las instituciones de seguridad. En días previos a que ocurrieran los hechos del linchamiento de Berenice, se publicó en los medios locales: "En su intento por reforzar la seguridad, el gobernador se arriesgó a involucrar a la sociedad en el combate a la delincuencia. Para ello, lanzó el plan de crear comités de vigilancia vecinales en los treinta y tres municipios" (Millán, 2013).

Es precisamente esta posibilidad de reunirse la que convierte a los pobladores en una masa en la cual pueden ejecutar acciones que de manera individual no realizarían, pues la responsabilidad se diluye entre los integrantes del grupo, generándose una sensación de poder invencible. $\mathrm{Al}$ eliminar la individualidad, resulta sencillo que las acciones sean contagiosas entre la masa, cuyos integrantes incluso pueden olvidarse de sus intereses individuales y buscar los intereses colectivos (Freud, 2007).

Con lo anterior, se evoca la cacería de brujas, la criminalización de todo lo que no cuadre con, por ejemplo en el caso de Berenice, el rol de mujer socialmente establecido. En dicho 
caso, todo lo hecho por la mujer linchada se convirtió en un caldo de cultivo perfecto para el estallido de la violencia y la generación del linchamiento tan sólo mediante cortas y sencillas instrucciones de quien tomó la dirección de la turba o fue investido como líder de la masa. En el caso que algún integrante hubiera intentado defender a Berenice, hubiera sido fácilmente considerado cómplice de la linchada, por lo que resultaría complicado y peligroso actuar en contra de los objetivos de la turba.

\section{El santo tribunal y los estereotipos de una buena mujer}

La violencia contra las mujeres es de distintas índoles. Las relaciones entre hombres y mujeres tienen una enorme carga de agresividad que es manifestada y expresada por ambos géneros de formas diferentes: los hombres tienen permiso de ejercer violencia en contra de las mujeres, y ellas deben padecerla con obediencia y resignación. Así, la violencia adquiere diferentes manifestaciones de acuerdo con quién la ejerce, contra qué tipo de mujer y con la circunstancia en que ocurre (Lagarde, 2011).

La violencia ejercida hacia Berenice en nuestro caso de estudio representa un fuerte ejemplo del esquema opresor que prevalece hacia las mujeres. Es la cosificación de la mujer, representada como un objeto del que se puede apropiar y disponer, dañarlo, con lo que se busca afirmar la supremacía masculina mediante un ejercicio de posesión y destrucción de dicho objeto. Se trata del ultraje en público de un cuerpo de mujer mediante el cual se lastima a su vez la integridad de las otras mujeres, esto sin considerar una violencia estructural que potencia y justifica este ultraje a través de legislaciones o normas (Molas, 2007).

De acuerdo con Bobbio (1994, citado en Salazar, 2008), la discriminación se sustenta en prejuicios que a su vez se configuran en tres etapas. Primeramente, se presenta la 
comprobación de una diferencia que distingue un nosotros de un los otros. Se trata de una simple contrastación de la diferencia basada en un rasgo físico o cultural. Enseguida, surge la evaluación positiva de ese rasgo y, por ende, la evaluación negativa de los que carecen de él. Finalmente, en la tercera etapa, el juicio de superioridad se transforma en legitimación del derecho de los superiores de dominar, someter, utilizar, maltratar y hasta exterminar a los pretendidamente inferiores. De esta manera, se pasa de la comprobación a la evaluación de una diferencia, y al empleo de esta como justificación de una acción discriminatoria, lo que a su vez le otorga a los sujetos una identidad como superiores o inferiores que, dependiendo del nivel de identificación, se convierte en una identidad colectiva.

Desde una perspectiva de género, la mujer debería tener un control estricto sobre su cuerpo y sus actividades como madre. Sin embargo, el esquema actual no considera dentro de sus posibilidades aspectos como la ostentación de un estado alcoholizado. En el caso de Berenice, la activación del estereotipo detonador de juicios y acciones (Amara, 1998) por los rasgos tanto físicos como de conducta asociados a ella se realizó mediante el siguiente proceso de clasificación:

Mujer desconocida en casa ajena=ladrona. De población vecina=intrusa. Cerca de un menor= secuestradora. Mujer secuestradora=contradice el estereotipo de estar naturalmente dotada para la crianza. En estado de ebriedad/drogada=mala mujer. Vestimenta no costosa (playera negra)=procedencia pobre. Físicamente no atractiva=poco femenina. Color de piel morena=procedencia indígena.

Este esquema se traduce en un proceso de criminalización en el que se encuentran presentes sexismo, racismo y clasismo. Al capturar a Berenice, la turba reúne la percepción de injusticia con los prejuicios y estereotipos de género, se despierta la compasión por la desgracia inmerecida hacia 
el niño supuestamente robado y su madre, y surge el temor de que la desgracia nos pueda pasar a nosotros. Cuando el capturado es alguien que no se considera como parte del nosotros, el mecanismo funciona de manera contraria: no se genera esta compasión, sino que se activa en el imaginario social el estereotipo de género mujer-madre-espacio privado, y ante la identidad contraria que en ese momento presenta Berenice (mujer-sola-espacio público-morenapobre), la identidad grupal y genérica de la turba se siente amenazada, lo que provoca, como señala Osborne (2012), discriminaciones múltiples bajo las cuales no se vive igual siendo una mujer de clase media y heterosexual que una lesbiana, indígena, o de un estrato social bajo.

La conducta de los pobladores a partir del estereotipo es lo que justifica las desigualdades: se trata despectivamente a la víctima, considerando que debió hacer algo para merecer ese sufrimiento. Esta mirada del castigo como merecido, adecuado y justificado libera a los atacantes moralmente, remontando a lo que Segato (2016) clasifica como una pedagogía de la crueldad, que no se intenta ocultar porque hay una voluntad clara de mandar un mensaje a la comunidad: la comunidad ha de verlo y ha de aprender una lección desde el terror.

Para cuando se llega a la racionalización de los actos cometidos en un linchamiento, se disfraza a este como un acto de justicia y corrección que defiende los intereses del grupo, lo cual lo justifica moralmente y genera su aceptación social. Sin estas creencias que justifiquen y racionalicen las desigualdades de las conductas, los pobladores que lincharon a Berenice tendrían que enfrentar al perturbador pensamiento de que lo ocurrido a Berenice podría fácilmente ocurrirles a ellos. 


\section{Aspecto jurídico}

La Secretaría de Gobernación publicó en el 2014 en el Diario Oficial de la Federación las reformas a diversos artículos de la Ley general para prevenir y sancionar los delitos en materia de secuestro y del Código Penal Federal con las que se duplican las penas por dicho ilícito. En el documento se especifica que el ministerio público procederá de oficio en todos los casos de secuestro, y que la sentencia condenatoria será emitida por un juez y deberá contemplar la reparación del daño a las víctimas, en términos de la ley.

En el caso de Berenice, si se considerara como un secuestro el ingreso al domicilio particular y el intento de extracción de la menor que las narraciones del hecho consignan, la pena aplicable para la mujer sería de noventa años de prisión y una multa de 4000 a 8000 días de salario mínimo, con una posible disminución de condena: "si espontáneamente se libera a la víctima del secuestro dentro de los tres días siguientes al de la privación de la libertad [...], la pena será de cuatro a doce años de prisión y de cien a trescientos días de multa" (Diario Oficial de la Federación, 2014, p. 4).

Para los pobladores que lincharon a Berenice, la pena dispuesta sería de cuatro a dieciséis años de prisión y de 1400 a 3000 días de salario mínimo como multa, esto por el desvío y la obstaculización de la investigación.

Desde una mirada distinta a la de los pobladores de Metepec, Berenice no tuvo oportunidad de probar su inocencia o de que se le comprobara su culpabilidad por el delito de secuestro. Con el linchamiento, existen los motivos para que la impartición de justicia se aplique hacia sus agresores, pues Berenice fue privada de su libertad y lesionada. Por tratarse de un caso de violencia contra la mujer, se debió aplicar el protocolo de investigación del delito de feminicidio, vigente en el estado de Morelos, para proceder a la inves- 
tigación de las violaciones cometidas con el fin de emitir sanciones a los responsables.

Sin embargo, el caso no fue atendido por las autoridades y quedó impune. Los que fueron identificados como autores del linchamiento no fueron juzgados, situación que priva en México como una forma de permisividad ante la comisión de dichos crímenes, lo cual agrava la problemática, pues se justifican los asesinatos culpabilizando a las víctimas y a sus familias al considerar que las mujeres agredidas no cumplen con los roles establecidos, lo que provoca que sean asesinadas. Es importante destacar que solamente el 4\% de los casos parecidos son sentenciados, aunque se desconoce si estas sentencias son condenatorias o absolutorias (OCNF, 2014).

El género de víctimas y agresores no es un aspecto importante en estas investigaciones:

El género de las víctimas sólo se toma en consideración como un dato, como si se tratara sólo de la clasificación de uno de los sexos queda fuera la clasificación binaria, sin contenido social ni de poder opresivo. En el extremo, se le da contenido prejuicioso y sí se toma en cuenta para señalar la evidente culpabilidad de la víctima. Así, se elude reconocer e investigar la condición de género de las víctimas niñas y mujeres y de los agresores que, en su inmensa mayoría, son hombres (Lagarde, 2008, p. 214).

Estas omisiones quedan claramente definidas como violencia institucional en la Ley general de acceso de las mujeres a una vida libre de violencia:

Son los actos u omisiones de las y los servidores públicos de cualquier orden de Gobierno que discriminen o tengan como fin dilatar, obstaculizar o impedir el goce y ejercicio de los derechos humanos de las mujeres, así como su acceso al disfrute de políticas públicas destinadas a prevenir, atender, investigar, sancionar y erradicar los diferentes tipos de violencia (Diario Oficial de la Federación, 2007, p. 5). 
En el caso del linchamiento de Berenice, destaca tanto en los pobladores como en las autoridades la amnesia selectiva en los días siguientes al hecho, pues el caso terminó en un acuerdo para implementar operativos que evitaran el robo de cosechas, con lo que se minimizó el delito y se solapó la complicidad de los pobladores para encubrir a los linchadores, con la convicción de que la culpa es de las autoridades por no brindar la seguridad adecuada. A más de un año del linchamiento de Berenice, apareció la siguiente nota:

Imparable violencia institucional contra las mujeres en Morelos [...]. En el caso de Ocuituco es claro que los tres poderes y los tres niveles de Gobierno están incumpliendo su obligación de proteger los derechos de las mujeres y ejerciendo violencia institucional [...]. Grave, muy grave que así sea, y de ninguna manera podemos permitirlo como sociedad, a menos de que nuestra indiferencia contribuya a perpetuar la impunidad y la injusticia. Ninguna mujer debe sufrir violencia. Basta de feminicidio en Morelos (Quintanilla y Palma, 20I4).

Así, la impunidad se convierte en un ciclo donde los antecedentes del linchamiento están en el hartazgo de los pobladores ante la impunidad, pero en lo posterior al asesinato de Berenice, y ante la falta de seguimiento del caso por parte de las autoridades, el resultado es la impunidad de los linchadores.

\section{Berenice en las redes sociales: la agonía virtual}

Dentro de la revisión de las notas periodísticas publicadas en internet, fuente principal que se utilizó para reconstruir la narración del caso de Berenice, también se observaron los foros abiertos y redes sociales en los que aparecían los comentarios cortos, que concentraban el pensamiento de su autor en pocas líneas, fraccionados, buscando generar polémica o ganar seguidores ante lo expresado. 
Por el tipo y la calidad del medio de comunicación que son los foros, los comentarios se publican de manera indiscriminada, y el carácter de incógnito del emisor evita que este se sienta amenazado. Puede suponerse que si la comunicación fuera cara a cara, los comentarios serían más cuidadosos. A continuación, se muestran algunos ejemplos, considerando los más llamativos o que reflejan una postura bien definida, ya sea a favor o en contra, y separándolos por categorías elaboradas por nosotros.

Con respecto a la sensación de cansancio y hartazgo por la impunidad de los delincuentes, causada a su vez por la corrupción y la falta de respuesta de las autoridades para impartir justicia, en los comentarios se intenta mostrar que la población tiene la capacidad y está decidida a defenderse de los delitos, enviando un mensaje de prevención para quien piense cometer uno: ${ }^{1}$

Está bien que se la chinguen, no queremos escoria en la ciudadanía, muy cabrona se iba a sentir si lograba secuestrarla y sepa Dios qué [sic] hacer con ella, si prostituirla o venderla o pedir lana [dinero] por la pobre niña [Anónimo].

El niño igual que otro[s] millones arrancados de sus familias, también son inocentes, que caen en manos de asquerosas "personas" como esta mujer, todos estamos cansados de que la ley no siempre es justa [Melissa].

I. Se reproducen textual y fielmente comentarios seleccionados hechos por usuarios en las notas publicadas por los medios digitales consultados y en sus respectivos foros de interacción. La información entre corchetes identifica el nombre o pseudónimo del autor del comentario dejado en el medio al momento de la recopilación de las notas. Se recomienda, para facilidad del lector, acudir a la bibliografía del presente artículo si desea consultar las notas revisadas. La información al momento en las páginas consultadas puede haber cambiado. Los medios consultados son Agencia Informativa (2013), Agencia Reforma (2013), Agencias (20 I3), Carrillo (20 I3a; 20 I3b), De la Fuente (20 I 3a; 20 I3b), González (20I3), La Policiaca (20I3), Notimex (20I4), Rojas (20I3a; 20I3b) y Staff (20I3). 
Y seguramente nadie levantará cargos en el ministerio público (seguramente por temor a represalias) y al no haber parte acusadora, esta mujer quedará libre, y seguirá haciendo de las suyas; como muchos otros personajes [Alejandra].

Pinches ladrones de niños de perdido ya saben lo que ahora les espera en ese lugar, ojalá y ese ejemplo cunda por toda la nación y les den su merecida [sic] rápido antes de que lleguen sus defensores e inútiles autoridades que sólo velarán por los delincuentes, no por los ciudadanos honestos [Drolean].

Estos comentarios responden a los casos de impunidad, aquellos en los que no se captura a los delincuentes, las denuncias no proceden o no hay pruebas que sustenten los cargos. Esta sensación evidenciada resulta en una percepción negativa sobre la aplicación de la justicia ante la cual, cuando se tiene la oportunidad, se hace justicia por propia mano, como en el caso de Berenice.

En el mismo orden de ideas, se encontraron comentarios que ponen en duda que Berenice fuera culpable de lo que la turba le imputaba:

La aplicación de las leyes y la justicia es lo que nos caracteriza de otros seres vivientes, no digo que perder a un hijo no sea una atrocidad, pero hay veces que se ha actuado de esta forma (linchamiento) y resulta que se hizo a personas inocentes [...]. ¿Entonces nuestras acciones son correctas? Esto es lo que, creo, nos hace igual a los criminales [Reyna].

Mete [sic] un poco de tristeza ver los comentarios de casi todos, creo que nos estamos convirtiendo en una sociedad insensible, [i]cómo puede ser posible que estén de acuerdo con los linchamientos[?] esto nos hace un[a] población tan bárbara como los criminales[.] ¿Quién tiene derecho a quitar una vida? ¿Hacer esto nos hace una sociedad mejor o peor? [Alfredo]. 
Veo en los comentarios que incluso los internautas se apresuran a linchar a la presunta "robachicos", con pocos elementos y ninguna prueba. Detrás de muchos linchamientos se oculta un delito que no tiene que ver con el que se pretende castigar [Ciudadano del Amor].

Increíble que muchos aquí aplaudan o mínimo justifiquen el intento de asesinato (porque eso es, asesinato). "Presuntamente quería"[,] o sea "presuntamente”[,] no "indudablemente”[.] ¿Dónde están las pruebas de su culpabilidad? [Fernanda].

Otros comentarios justifican el linchamiento y muestran una situación empática con las supuestas víctimas del delito cometido por Berenice. Muestra de ello son los siguientes:

La delincuencia ha rebasado el sentir humano de las personas, porque ¿quién no haría lo mismo si se topara con quien pretenda robarle lo más querido del ser humano, un hijo, o que se lo han robado y nunca vuelve a saber de él? Así de simple[s] son las situaciones [Reyna].

Quizá muchos podrán decir que son inhumanos[,] pero quien se atreve a robar un niño se merece eso y más, ya que este acto[,] de realizarse[,] destroza la vida de la familia y del niño, si yo fuera el padre del niño ni lo dudo, allí mismo le doy en su madre [sic] no importa que sea mujer. Quien tenga hijos me dará la razón [Juan].

Relacionados con la percepción de impunidad y la justificación de los linchamientos, se encontraron también comentarios relacionados con propuestas de castigo o pena:

Que la cuelguen lo más despacio posible... para que sienta el dolor de unos padres desconsolados [Xavier].

Termínenla y donen sus órganos si es que sirven para algo, sino [sic] pues alimento pa' los peces [sic] o para los estudiantes de medicina [Anónimo]. 
Aquí no entra[ba] la conciencia de los pobladores, ni el karma, ni derechos humanos ni siquiera dios[,] vaya, aquí sólo aplicaba la muerte lenta [Econotintas].

Así, en los comentarios analizados prevalece la falta del espíritu crítico y la sensibilidad hacia el otro. En ellos parece comunicarse mucho, pero se hace de forma rápida y superficial (Hirigoyen, 2008). También, se expresan los prejuicios discriminatorios, atribuyendo a los otros la razón de nuestros miedos, malestares, incertidumbres y dificultades surgidos espontáneamente como reacción al daño, molestia o dificultad que causa una noticia que implica un rasgo distintivo discordante con los rasgos del grupo al que pertenecemos (Bobbio 1994, citado en Salazar, 2008).

Prince (1982) define estas opiniones contrarias como una narrativa de conflicto que da cuenta de la interacción humana. En este tipo de narrativas resulta útil el análisis crítico de discurso, junto con la perspectiva de género, para identificar cómo y quién construye los discursos de la violencia de género, además del comportamiento de las personas como agentes pasivos o activos de la violencia, pero principalmente, visibilizando las estructuras discursivas que representan, confirman, legitiman, reproducen o desafían las relaciones de abuso de poder del sistema sexo-género-clase-etnia en la sociedad y, finalmente, la reproducción y resistencia de las relaciones de poder e ideologías dominantes.

\section{Propuestas de intervención}

La violencia colectiva en los linchamientos se considera desde una perspectiva de la violencia humana, es decir, dada entre individuos racionales y no como violencia patológica -para la que la agresividad es un componente instintivo del ser humano utilizado como mecanismo de 
supervivencia ante determinadas condiciones de peligro del contexto-. Por lo tanto, en coincidencia con la postura de la OMS, la violencia como un fenómeno humano puede ser prevenible, es decir, se pueden prever algunos tipos de violencia -en nuestro caso, la violencia de géneropara mitigar otras manifestaciones violentas, como los linchamientos por motivos de género (por el hecho de ser mujer). Esta mitigación permitiría dar solución a los conflictos sin llegar a la violencia.

Con eso en mente, se ha diseñado la propuesta presentada en esta parte del artículo. El planteamiento que se hace no obvia los pasos comunes en una intervención, pero tampoco se considera como una receta aplicable a poblaciones distintas, sino que se propone que se estructure en dos modalidades: de prevenciones universales, que se ofrecen o se aplican a la población en general, y dirigidas, que se aplican a un subconjunto de la población general (Lutzker, 2008).

En las estrategias universales se encuentran las que están establecidas en leyes y códigos, pero que no se están cumpliendo de manera adecuada. Entran en este conjunto de estrategias aquellas destinadas a hacer que se apliquen las leyes y se investiguen los delitos cometidos contra las mujeres, respetando los tratados de las convenciones para prevenir, sancionar y erradicar la violencia y la discriminación contra las mujeres y, por lo tanto, buscando también que las sentencias incorporen el respeto de los derechos humanos, la perspectiva de género y el seguimiento de los protocolos de atención a las víctimas. En el caso de los Gobiernos estatales, estas estrategias suponen que estos deberían atender de manera oportuna las recomendaciones sobre las alertas de violencia de género para generar una mejora real de las condiciones de impartición de justicia y atención de las mujeres víctimas.

El enlace entre las estrategias universales y las dirigidas son los mecanismos de vigilancia de incidencia de delitos 
que son implementados por los Gobiernos y encargados de seguridad. En ellos, se determinan los posibles factores de riesgo y las estrategias de intervención dirigidas según la edad, género, nivel socioeconómico, historia personal, raza u origen étnico, valores, actitudes y tradiciones, en el entendido de que estos diagnósticos son el sustento que determina conductas violentas que deben ser consideradas para disminuir la violencia de género en determinadas áreas geográficas.

En las estrategias de intervención dirigidas, se busca neutralizar y desmontar los prejuicios, por lo que es indispensable encontrar la vía para reformular y redefinir legal e institucionalmente tales objetivos (Bobbio, 1994, citado en Salazar, 2008). Para implementar intervenciones dirigidas, se requiere el análisis de las capas de sedimentación que determinan el comportamiento de los integrantes de un grupo, en las que en el nivel central -núcleo y parte más sólida- se encuentra la cultura encargada de mantener los símbolos más elementales y una estructura de valores, normas y una manera de pensar -independientemente de la identidad-.

Es decir, este nivel central de las capas de sedimentación del grupo ofrece una cultura que define y orienta la conducta del mismo en forma duradera, regulando las relaciones sociales, y estabiliza los roles y los comportamientos mediante procesos de reclutamiento, formación, socialización y exclusión de miembros (Gallino, 2001; Enríquez, 2002).

Por su parte, las capas exteriores, que conforman la periferia, van siendo menos densas, de tal forma que son más susceptibles a sufrir modificaciones (Castoriadis, 2007). Es en ellas donde se originan los procesos instituyentes (de cambio e innovaciones), y en las que estos tiene un mayor impacto, pues conforme se aproximan al centro -sólido, erosionado- requieren de mayor fuerza y constancia para 
lograr que se legitimen y perduren, formando con el paso del tiempo parte del nivel central.

Es por ello que la propuesta de intervención se ubicaría en estas capas exteriores, considerando las categorías del estilo institucional (Fernández, 2005) adaptadas a conceptos de violencia de género:

- Técnicas y modelos que orienten la acción y controlen los desvíos. Resulta necesario que se difunda y sensibilice a la población sobre la existencia del derecho -humanode las mujeres a una vida libre de violencia y sobre las leyes que la protegen.

- Modos de reaccionar frente a las dificultades. Poner a disposición de la población y capacitar a las autoridades sobre los protocolos que consideran aspectos de género para los casos de violencia contra las mujeres y la aplicación del protocolo de feminicidio, con lo que se abre el abanico de alternativas de atención.

- Formas de percibir y juzgar la realidad. Mostrar a la población los procesos a través de los cuales se atienden los delitos relacionados con la violencia de género, lo que colaborará a modificar la percepción de impunidad.

- Modalidades de comunicación e interacción. Establecer esquemas de comunicación oportunos entre las autoridades, las víctimas y la población respecto al curso que siguen las investigaciones. Resulta indispensable identificar los métodos de comunicación culturalmente significativos para cada población.

- Modalidades de distribución de poder y responsabilidades. Reforzar en la población la noción de que en un Estado de derecho los encargados de aplicar la justicia son las autoridades y no los pobladores y que aplicar justicia por propia mano es un delito.

- Modalidades de control y distribución de conocimientos. Generar programas de intervención con temas de 
equidad de género en poblaciones identificadas con problemas de violencia.

Resulta necesario que se apoyen programas que trabajen en prevención de todos los tipos de violencia contra las mujeres considerando las anteriores categorías, mismas que deben ser adecuadas a lo obtenido en los diagnósticos. Cuando se avanza en las categorías mencionadas de acuerdo a esquemas propios de cada población, se va permeando en aspectos arraigados de la cultura como los prejuicios y estereotipos.

Ambos esquemas de intervención (universales y dirigidos) deben ser propuestos en periodos prolongados de tiempo para que tengan un verdadero impacto y pasen a la parte central de la cultura, es decir, se sedimenten. Estas propuestas de intervención deben ser relevantes en términos culturales para la población a la que van dirigidas. El principio básico será siempre que tener una vida libre de violencia es un derecho humano de las mujeres reconocido por las leyes nacionales e internacionales.

\section{Conclusiones}

Los linchamientos son un tema poco investigado. Esta situación genera que, para estudiarlos, se retomen los desarrollos conceptuales y teóricos sobre la violencia entre individuos y grupos, a los que se les deben anexar los aspectos de poder. Para comprender mejor los antecedentes del linchamiento, se debe explicar la forma en que la violencia se instituye, es decir, cómo se da el proceso de institucionalización a manera de camuflaje cultural mediante aspectos de violencia cotidiana de género que pasa desapercibida.

Los prejuicios en contra de las mujeres están constituidos por creencias bien atrincheradas, derivadas de opiniones generalizadas. Por ello resultan tan difíciles de modificar, tan impermeables a los argumentos y a las pruebas 
empíricas que incluso derivan en acciones y actitudes muy despectivas y crueles, es decir, discriminaciones que humillan, oprimen, excluyen y hasta matan a mujeres inocentes por el solo hecho de tener las características que generan repulsión al grupo (Bobbio 1994, citado en Salazar, 2008). A esto se suma la violencia institucional, mediante las omisiones de los órdenes de Gobierno para cumplir con su obligación de garantizar el derecho de las mujeres a una vida libre de violencia.

El acto en contra de Berenice tiene una importancia fundamental. Anudando una violencia sin freno ejercida por una masa, los estereotipos e inequidades de género alcanzan su punto más alto, y el esquema de justicia instituido pierde todo su poder antes, durante y después de un evento de linchamiento.

Por su parte, los foros y las redes sociales permiten el paso de víctimas en la vida real a verdugos implacables en la virtualidad: de manera rápida y sencilla, otorgan la posibilidad de juzgar al otro considerando solamente la versión de la nota periodística, sin advertir que se exponen miedos e inconformidades, en este caso sobre el género femenino, en los comentarios hechos en dicha virtualidad.

Es necesario realizar un mayor número de estudios en los que se revisen los linchamientos de mujeres como esquemas de control social a partir de la sumisión y obediencia de las mujeres a reglas establecidas por los hombres. Para su estudio, se debe reconocer la complejidad de los procesos de violencia social e institucional sustentada en ideologías patriarcales, eurocéntricas y capitalistas que vulneran a ciertos grupos de mujeres, a quienes se les niega el poder y se les condena a ser ciudadanos de segunda por su etnia, clase social u orientación sexual.

La precisión de que la violencia es un acto deliberado elimina el debate sobre la violencia como acción innata y fija la postura de que, exceptuando las patologías y distin- 
guiéndola de la agresividad, la violencia resulta de una construcción cultural, y por lo tanto, así como se aprende, puede ser desaprendida, lo que da cabida a los esquemas de intervención para disminuirla y erradicarla.

Agencia Informativa (I8 de julio de 20I3). "Intentan linchar a una mujer en Metepec, la dejan inconsciente”. Agenda Informativa de México. Recuperado de:http://agendainformativa.com.mx/2013//8/07/intentan-linchar-a-una-mujeren-metepec-la-dejan-inconsciente/

Agencia Reforma (18 de julio de 2013). "Intentan linchar a mujer en Morelos". Somos Frontera. Recuperado de: http:// www.somosfrontera.com/mexico/ci_23685569

Agencias (20 de julio de 20I3)."Rescatan a mujer de intento de linchamiento”. Zócalo Saltillo. Recuperado de: http:// www.zocalo.com.mx/seccion/articulo/rescatan-a-mujerde-intento-de-linchamiento- 1374302303

Amara, G. (1998). Cómo acercarse a... la violencia. México: Conaculta.

Bourdieu, P.(20I0). La dominación masculina. España: Anagrama. Carrillo, L. (08 de agosto de 20I3a). “Era vecina de Yautepec mujer lacerada en Metepec". Interdiario. Recuperado de: http://www.interdiario.info/2013/08/era-vecina-deyautepec-mujer-lacerada-en-metepec/

Carrillo, L. (26 de agosto de 20 I3b)." "Frena SSP investigaciones sobre linchamiento en Metepec". Interdiario. Recuperado de:http://www.interdiario.info/20I3/08/frena-ssp-investigaciones-sobre-linchamiento-en-metepec/

Castoriadis, C. (2007). La institución imaginaria de la sociedad. Buenos Aires: Tusquets Editores.

De la Fuente, C. (19 de julio de 2013a). "Intentan linchar a mujer por rapto en Ocuituco”. Diario de Morelos. Recuperado de: http://www.diariodemorelos.com/article/ intentan-linchar-mujer-por-rapto-en-ocuituco 
De la Fuente, C. (2 I de julio de 20 I 3b).“Está en coma, la mujer linchada en Ocuituco". Diario de Morelos. Recuperado de: http://www.diariodemorelos.com/article/est\%C3\%AIen-coma-la-mujer-linchada-en-ocuituco

De la Fuente, C. (I 5 de diciembre de 20 I3c).“Desarma mujer a un robabolsos”. Diario de Morelos. Recuperado de:http:// www.diariodemorelos.com/article/desarma-mujer-unrobabolsos

Diario Oficial de la Federación (2007). Ley general de acceso de las mujeres a una vida libre de violencia. Recuperado de: http://www.diputados.gob.mx/LeyesBiblio/ref//gamvlv/ LGAMVLV_orig_0Ifeb07.pdf

Diario Oficial de la Federación (20I4). Ley general para prevenir y sancionar los delitos en materia de secuestro. Recuperado de: http://www.diputados.gob.mx/LeyesBiblio/pdf/ LGPSDMS_0306I4.pdf

En serio noticias (23 de julio de 20I3)." Muere mujer linchada en Ocuituco". Recuperado de: https://www.facebook. com/EnSerioNoticias/posts/542953829086865.

Enríquez, E. (2002). La institución y las organizaciones en la educación y la formación. Buenos Aires: Universidad de Buenos Aires.

Fernández, L. (2005). Instituciones educativas: dinámicas institucionales en situaciones críticas. Buenos Aires: Paidós.

Foucault, M. (20I0). Michel Foucault, obras esenciales. España: Paidós.

Freud, S. (2007). Psicología de las masas. España: Alianza Editorial.

Gallino, L. (200I). Diccionario de sociología. México: Siglo XXI Editores.

Geertz, C. (2005). La interpretación de las culturas. Barcelona: Gedisa.

Gizburg, C. (200I). El queso y los gusanos. España:Atajos. 
Bibliografía

González, R.(I8 de julio de 20 I3).“Intentan linchar a mujer en Morelos". ElArsenal. Recuperado de:http://www.elarsenal. net/2013/07/18/intentan-linchar-a-mujer-en-morelos/

Hirigoyen, M. (2008). Las nuevas soledades. España: Paidós.

Iñiguez, L. (2003). Análisis del discurso. Manual para las ciencias sociales. Barcelona: UOC.

La Policiaca (I8 de julio de 2013). "Frustran linchamiento de mujer en Morelos”. Recuperado de: http://www.lapoliciaca.com/nota-roja/frustran-linchamiento-de-mujeren-morelos/

La Policiaca (I4 de agosto de 20I3b). "Se reúne SSP con pobladores de Metepec”. Recuperado de: http://www. lapoliciaca.com/nota-roja/se-reune-ssp-con-pobladoresde-metepec/

Lagarde, M. (2008). Antropología, feminismo y política: violencia feminicida y derechos humanos de las mujeres. España: Ankulegi. Recuperado de: http://www.campoalgodonero. org.mx/sites/default/files/documentos/Violencia\%20 feminicida.pdf

Lagarde, M. (20I I). Los cautiverios de las mujeres: madresposas, monjas, putas, presas y locas. México: UNAM.

Lutzker, J. (2008). Prevención de la violencia: investigación y estrategias de intervención basadas en evidencia. México: Manual Moderno.

Millán, A. (08 de agosto de 20/3). "Inseguridad: levantamiento". El Sol de Cuernavaca. Recuperado de: http:// www.oem.com.mx/elsoldecuautla/notas/n308 I 264.htm

Molas, M. (2007). Violencia deliberada, raíces de la violencia patriarcal. Barcelona: Icaria.

Muchembled, R. (20I0). Una historia de la violencia. España: Paidós.

Notimex (03 de junio de 20I4)."Segob publica nuevas penas para secuestradores". El Financiero. Recuperado de:http:// www.elfinanciero.com.mx/sociedad/segob-publicanuevas-penas-para-secuestradores.html 
OCNF (20I4). Estudio de la implementación de tipo penal de Bibliografía feminicidio en México. México: Observatorio Ciudadano Nacional de Feminicidio.

OMS (2002). Informe mundial sobre la violencia y la salud. Recuperado de:http://www.who.int/violence_injury_prevention/ violence/world_report/es/summary_es.pdf

OMS (2016). Violencia contra la mujer. Recuperado de: http:// www.who.int/mediacentre/factsheets/fs239/es/

Osborne, R. (Coord.) (2012). La situación social de la población migrante latinoamericana TLGB (transexual, transgénero, lesbiana, gay y bisexual) en España desde un enfoque de género y derechos humanos. Santo Domingo: ONU. Recuperado de: https://dialnet.unirioja.es/servlet/libro?codigo $=655787$

Prince, G. (1982). The form and functioning of narrative. Nueva York: Mouton.

Quintanilla, J., y Palma, A. (I5 de septiembre de 2014). "Imparable violencia institucional contra las mujeres en Morelos". La Jornada Morelos. Recuperado de: http://www. jornadamorelos.com/2014/9/15/sur_nota_02.php

Ricoeur, P. (2009). Tiempo y narración I. México: Siglo XXI.

Rojas, L. (19 de julio de 2013a). “iSalvaje golpiza!”. El Sol de Cuautla. Recuperado de: http://www.oem.com.mx/ elsoldecuautla/notas/n3058447.htm

Rojas, L. (08 de agosto de 20I3b)."Falleció en el hospital, tras severa golpiza; acusada de intentar raptar a un menor". El Sol de Cuautla. Recuperado de: http://www.oem.com. $\mathrm{mx} / \mathrm{elsoldecuautla/notas} / \mathrm{n} 308$ I | $43 . \mathrm{htm}$

Salazar, L. (2008). Democracia y discriminación. México: Consejo Nacional para Prevenir y Erradicar la Discriminación.

Sánchez, M. (2007). “Mujeres y estrategias pacíficas de resolución de conflicto: el análisis de las sociedades prehistóricas", en M. Molas Font (Ed.), Violencia deliberada, las raíces de la violencia patriarcal (pp. 39-55). Barcelona: Icaria. Segato, R.(2016). La guerra contra las mujeres. Madrid:Traficante de Sueños. 
Bibliografía

Staff (24 de julio de 20 I 3).“Indaga PG asesinato de Ocuituco”. Diario de Morelos. Recuperado de: https://www.diariodemorelos.com/article/indaga-pgj-asesinato-de-ocuituco Tonantzin, P. (I8 de julio de 20|3). "Policía rescata a mujer de ser linchada tras intento de robo de niña”. Excelsior. Recuperado de: http://www.excelsior.com.mx/nacional/ 2013/07/I8/909492\#imagen-I

Tornero, A. (2008). "El tiempo, la trama y la identidad del personaje a partir de la teoría de Paul Ricoeur". Revista de humanidades, (24), 5I-79.

Van Dijk,T. (2002)."El análisis crítico del discurso y el pensamiento social". Athenea Digital. Revista de pensamiento e investigación social, ( I), I8-24.

Van Dijk, T. (2009). Discurso y poder. Barcelona: Gedisa. 